\title{
Pandemia: vivências de médicos da atenção primária à saúde e de mestrandos em Saúde da Família
}

\section{Pandemic: experiences of primary health care doctors and master's degree students in family health}

\author{
Divanise Suruagy Correia' (D) | divanisesuruagy@gmail.com \\ Maria das Graças Monte Mello Taveira' (D) montegraca@gmail.com \\ Celso Marcos da Silva1 (D) celsomarmed.ufal@gmail.com \\ Michael Ferreira Machado' (D) michael.machado@arapiraca.ufal.br \\ Cristina Camelo Azevedo' ${ }^{1}$ (D) cris.camelo@gmail.com \\ Carlos Dornels Freire de Souza' (1D) carlos.freire@arapiraca.ufal.br
}

\section{RESUMO}

Introdução: A Covid-19 trouxe uma série de desafios para o Sistema Único de Saúde. Na atenção primária à saúde (APS), tais desafios se somam aos já existentes.

Objetivo: Este estudo teve como objetivo analisar a vivência de enfrentamento da pandemia de Covid-19 entre médicos do Programa Mais Médicos Brasil, mestrandos em Saúde da Família e atuantes na APS.

Método: Trata-se de estudo qualitativo envolvendo oito médicos da APS de Alagoas que cursam o Mestrado Profissional em Saúde da Família (PROFSAÚDE). Foram elaboradas cinco questões, cujas respostas foram analisadas com base na teoria de Análise de Conteúdo.

Resultado: Observaram-se três categorias e quatro subcategorias: categoria 1 - "Processo de estudo e de trabalho" (subcategoria 1.1 "Características do PROFSAÚDE" - e subcategoria 1.2 - "Estratégias pessoais desenvolvidas"), categoria 2 - "Desafios no gerenciamento da vida" (subcategoria 2.1 - "Mudanças no cotidiano" - e subcategoria 2.2 - "Impacto nas emoções") e categoria 3 - "Crescimento pessoal e profissional".

Conclusão: Em tempos de pandemia, os profissionais médicos vivenciam situações complexas e dinâmicas em razão de um duplo e acumulativo processo - o trabalho na APS e a condição de mestrando. Apesar de todas as dificuldades enfrentadas, o mestrado possibilitou o aprimoramento das habilidades em lidar com situações críticas.

Palavras-chave: Covid-19; Educação Médica; Humanidades; Atenção Primária à Saúde.

\section{ABSTRACT}

Introduction: COVID-19 has brought numerous challenges for the Health System in Brazil. In Primary Health Care, these challenges add to those that already exist.

Objective: To analyze the experience of facing the COVID-19 pandemic among doctors of the Mais Médicos Brasil Program and master's degree students in Family Health and those working in Primary Health Care.

Methods: Qualitative study involving eight doctors from Primary Health Care in Alagoas who are also studying the professional master's degree in Family Health (PROFSAÚDE). Five questions were developed, the answers to which were analyzed based on Content Analysis theory.

Results: Three categories and four subcategories were observed: Category 1 - Study and work process (Subcategory 1.1- Characteristics of PROFSAÚDE; Subcategory 1.2 - Personal strategies developed); Category 2 - Challenges in Life Management (Subcategory 2.1 - Changes in daily life; Subcategory 2.2 - Impact on emotions) and Category 3 - Personal and Professional Growth.

Conclusion: During the pandemic, medical professionals experience complex and dynamic situations due to a dual and cumulative process working in PHC and studying for their master's degree. Despite all the difficulties faced, the master's degree allowed them to improve skills in dealing with critical situations.

Keywords: Covid-19; Medical Education; Humanities; Primary Health Care.

${ }^{1}$ Universidade Federal de Alagoas, Maceió, Alagoas, Brasil.

Editora-chefe: Daniela Chiesa

Editora associada: Izabel Cristina Meister Martins Coelho

Recebido em 13/08/20; Aceito em 11/03/21.

Avaliado pelo processo de double blind review. 


\section{INTRODUÇÃO}

No final de 2019, um surto de pneumonia viral de origem desconhecida foi identificado em Wuhan, na China. No início de janeiro, o novo coronavírus (2019-nCoV) foi sequenciado e identificado como responsável pelo surto em Wuhan. Posteriormente, passou a ser chamado de coronavírus da síndrome respiratória aguda grave 2 (severe acute respiratory syndrome coronavirus 2 - Sars-CoV-2) e a doença causada por ele foi denominada coronavirus disease 2019 (Covid-19) ${ }^{1}$. No Brasil, confirmou-se o primeiro caso em 26 de fevereiro de 2020, e a primeira morte ocorreu em 17 de março ${ }^{2}$. Em 11 de março de 2020, ganha o status de pandemia ${ }^{3}$.

A pandemia da Covid-19 trouxe uma série de desafios para os sistemas de saúde do mundo, sobretudo para os países de baixa e média rendas. No Brasil, a Carta Magna institui a saúde como um direito fundamental de todos e dever do Estado (artigo 196 da Constituição Federal de 1988)4. O dispositivo constitucional aludido consagra o nascimento do Sistema Único de Saúde (SUS).

A forma de organização do SUS prioriza e privilegia a atenção primária à saúde (APS) como coordenadora e organizadora do cuidado5. Por meio da Estratégia Saúde da Família (ESF) e das equipes de apoio matricial, a APS possibilita uma resposta coordenada aos problemas de saúde. É porta de entrada das pessoas ao SUS, e a partir dela se coordena o acesso a serviços especializados ${ }^{5,6}$.

Entre as muitas ações desenvolvidas para o fortalecimento da APS no Brasil, destaca-se o Programa Mais Médicos Brasil (PMMB). Criado em 2013, tem como intenção preparar recursos humanos na área médica para o SUS, além de atenuar a deficiência de médicos nas regiões mais vulneráveis do país, ampliando a oferta de serviços na APS7.

OMestrado Profissional em Saúde da Família (PROFSAÚDE) foi aprovado em 2016 pela Coordenação de Aperfeiçoamento de Pessoal de Nível Superior (Capes) e é ofertado em rede nacional liderado pela Fundação Oswaldo Cruz (Fiocruz). Utiliza o Sistema Universidade Aberta do Sistema Único de Saúde (UNA-SUS), tendo o Ministério da Saúde e o Ministério da Educação como instituições demandantes e financiadoras ${ }^{8}$.

Em tempo de pandemia, é salutar compreender os desafios impostos aos profissionais da APS em suas vivências no processo de cuidado. Vivenciar algo é experienciar. Tratase de um processo psicossocial que consiste essencialmente em assimilação e participação no todo, no qual o indivíduo se posiciona, atribui valor e supõe uma ação ativa perante uma situação. A vivência está associada a diversos campos e formas, caracterizando-se por meio da aprendizagem profunda?

Ao ingressar em um programa de mestrado, o discente carrega vivências de toda a sua formação, desde a educação básica, a graduação até a pós-graduação que interferem em seu caminhar no curso. Dessa forma, objetiva-se por meio deste trabalho analisar a vivência de enfrentamento da pandemia de Covid-19 entre médicos do PMMB, mestrandos em Saúde da Família e atuantes na ESF.

\section{MÉTODO}

Foi realizado um estudo qualitativo e observacional envolvendo oito profissionais médicos, de ambos os sexos, na faixa etária de 30 a 40 anos, mestrandos do PROFSAÚDE, atuantes na ESF em Alagoas, em junho de 2020.

Utilizou-se como instrumento para coleta dos dados um questionário elaborado pelos pesquisadores com aspectos relacionados a: sexo, idade e cinco perguntas abertas versando sobre a vivência das atividades como profissional, médico e mestrando, estratégias para conciliar estudo e trabalho, mudanças na vivência durante a pandemia e impactos da pandemia em sua vida. $O$ instrumento para coleta dos dados consistiu em um formulário eletrônico on-line individual, viabilizado por meio do aplicativo Google Docs ${ }^{\circledR}$, enviado ao e-mail pessoal de cada participante do estudo.

As respostas foram consolidadas em uma planilha do Excel $^{\circledR}$ e transcritas para planilhas seguindo a teoria de Análise de Conteúdo e o modelo baseado em Malheiros ${ }^{10}$. Os passos foram realizados por três autores e comparados posteriormente, a fim de evitar fatores de confundimento.

Os dados foram analisados manualmente em quatro etapas. A primeira consistiu na organização das respostas registradas no instrumento de coleta e na busca de ideias centrais que emergiram dessas respostas. Essa pré-análise caracterizouse pela leitura aprofundada, detalhada e cuidadosa na busca de estabelecer uma categorização dos dados que correspondesse à identificação da unidade de contexto.

Na segunda etapa, elaborou-se mais uma planilha, na qual se registraram as ideias explícitas - denominadas de categorias provisórias - e implícitas - denominadas de focos -, quando se buscaram os sentidos. Malheiros ${ }^{10}$ orienta a observação de três princípios para a elaboração dessa etapa:

- Exclusão: um dado ou um conjunto de dados é excluído das demais categorias quando se identifica seu pertencimento a uma categoria específica.

- Pertinência: quando um dado não pode ser integrado a uma categoria por falta de escolha, é necessário que ele seja pertinente à categoria no qual foi enquadrado.

- Objetividade: a ligação de um dado a uma categoria deve ser efetuada de forma clara, sem sofrer qualquer influência da subjetividade, para 
que não prejudique a organização dos resultados da pesquisa.

A terceira etapa consistiu na elaboração de nova planilha e busca responder ao objetivo da pesquisa, por meio das unidades de registro, relacionando-se fala e foco/tema. Nesse momento, busca-se a identificação do sentido da inferência, exemplificando no texto como se chegou ao resultado.

Na quarta etapa, foram produzidas duas planilhas. Em uma, interpretam-se os focos e suas unidades de registros, finalizando com a preparação de uma síntese para cada foco. $\mathrm{Na}$ outra planilha, elaboraram-se ideias que correspondem às categorias e às suas respectivas subcategorias.

Para apresentação das respostas, preservou-se o anonimato dos pesquisados, razão pela qual os dados mostram nomes fictícios a eles associados. O projeto foi aprovado pelo Comitê de Ética da Universidade Federal de Alagoas (Ufal) sob o Parecer n ${ }^{\circ} 4.130 .950$ - Certificado de Apresentação para Apreciação Ética (CAAE) n॰ 33045020.2.0000.5013.

\section{RESULTADOS E DISCUSSÂO}

A história mostra que uma pandemia provoca impacto na vida das pessoas. No caso da atual pandemia da Covid-19, trata-se de um grande desafio para a saúde pública mundial diante das características da doença, de rápida propagação na população, e necessidade de mudanças abruptas nas rotinas das instituições de saúde, causadas pelo grande número de internações hospitalares necessárias em decorrência das complicações dos quadros clínicos ${ }^{2,3,11-13}$.

A análise dos dados da pesquisa possibilitou a identificação de três categorias e quatro subcategorias (Quadro 1).

As categorias e suas subcategorias serão apresentadas e discutidas a seguir.

\section{Categoria 1: Processo de estudo e de trabalho}

A pós-graduação stricto sensu promove o desenvolvimento científico, bem como a transformação de vida dos pós-graduandos. Frequentar um curso desse porte traz sentimentos de ambivalência para os discentes, pois, ao mesmo tempo que vivenciam situações que geram prazer, como a aquisição de novos conhecimentos, o reconhecimento de seus trabalhos realizados e a descoberta de novos contextos por meio de pesquisa, deparam-se também com momentos de ansiedade e sofrimento, como a cobrança/necessidade de muito estudo, de produção de publicações/artigos, além do cumprimento de prazos $^{14}$.

Trata-se de exigências internas e externas que impactam a vida dos discentes ${ }^{14}$, além do entrelaçamento de responsabilidades, aspectos familiares e financeiros
Quadro 1. Distribuição das categorias e subcategorias correspondentes, 2020

\begin{tabular}{lc}
\hline \multicolumn{1}{c}{ Categoria } & Subcategoria \\
\hline $\begin{array}{l}\text { 1. Processo de estudo e de } \\
\text { trabalho }\end{array}$ & $\begin{array}{c}\text { Características do } \\
\text { PROFSAÚDE } \\
\text { Estratégias pessoais } \\
\text { desenvolvidas }\end{array}$ \\
\hline $\begin{array}{l}\text { 2. Desafios no } \\
\text { gerenciamento da vida }\end{array}$ & $\begin{array}{c}\text { Mudanças no cotidiano } \\
\text { Impacto nas emoções }\end{array}$ \\
\hline 3. Crescimento pessoal e profissional \\
\hline
\end{tabular}

que provoca mudanças sociais e demográficas. Isso expõe os discentes a pressões e incertezas em relação à carreira profissional, o que resulta em estresse, competitividade e problemas interpessoais, e esse cenário exige automotivação e enfrentamento de vulnerabilidades ${ }^{15}$.

\section{Subcategoria 1.1: Características do PROFSAÚDE}

O PROFSAÚDE, por ser um mestrado semipresencial, apresenta características diferentes dos demais programas presenciais $^{8}$. Os pesquisados informam que, por suas características, o mestrado possibilita a participação de profissionais que estão no serviço, proporcionando a conciliação de atividades do serviço e de estudo com as do mestrado, o que seria mais distante em outras modalidades, uma vez que teriam que se deslocar em períodos preestabelecidos do serviço, e isso exigiria maior afastamento das atividades assistenciais.

A literatura aponta para evidências que mostram que há associação entre a satisfação com a estrutura formal do programa stricto sensu e a possibilidade de conclusão do curso, além de contribuir para o bem-estar dos acadêmicos ${ }^{15}$. Foram citadas facilidades e dificuldades no processo de trabalho relacionado às características do mestrado. Como facilidade, mencionou-se o fato de estar ao mesmo tempo no campo de trabalho e no de estudo:

Facilita a operacionalização de minha linha de pesquisa e gerando a possibilidade de construir um produto que traga resolutividade aos eventos que os acometem (João).

A possibilidade de aplicar o conteúdo aprendido e propor mudanças em uma realidade de que é próxima a nós (Betânia).

Comodidade de realizar as atividades em casa; possibilidade de criar o próprio cronograma (Josefa).

Entre as dificuldades, os participantes apontaram as seguintes:

A gestão do tempo, dar conta das leituras e atividades 
das disciplinas. Pensei alguns momentos em desistir por esse desafio, mas estou persistindo (André).

Conciliar as atividades do curso com o trabalho e as relações familiares, o distanciamento com professores, apesar da comunicação via fóruns [...] (Pedro).

Associar trabalho e estudo pode influenciar na permanência do profissional médico no PMMB. A evasão é bastante estudada na graduação, todavia, na pós-graduação, o tema é ainda pouco explorado, apesar de ser uma preocupação dos coordenadores e docentes/orientadores, carência que reflete no panorama de dados de um diagnóstico dessa evasão nos mestrados. Entre os vários fatores que influenciam no abandono de um curso, encontra-se o financeiro ${ }^{16}$, o que é contemplado no PROFSAÚDE8, uma vez que o profissional continua atuando em sua área.

\section{Subcategoria 1.2: Estratégias pessoais desenvolvidas}

Apesar das facilidades apontadas no processo de estudo e trabalho, os discentes, para que pudessem alcançar os objetivos, precisaram desenvolver estratégias pessoais para enfrentar as dificuldades também relatadas. Eles tiveram que estabelecer mecanismos para a gestão do tempo e o domínio das ferramentas digitais, aspectos fundamentais para a realização das atividades do mestrado. Entre as estratégias, destacaram-se as seguintes:

Agenda programada semanal das atividades. Grupo de WhatsApp com os colegas para um dar apoio ao outro. Conversa com professor do mestrado sobre dificuldades (Severino).

Focar, objetivar não pular etapas do que é oferecido e solicitado, o que estudei e aprendi, apliquei na vida diária, no ensino, serviço e vida familiar (Sebastiana).

A negociação com a família do tempo dedicado ao estudo ("além do trabalho que já retira o profissional médico do convívio familiar") foi necessária entre os pesquisados. Um dos fatores de evasão encontrados por Cardoso ${ }^{16}$ foi a influência familiar, associado às questões de trabalho, o que é bem revelado nos textos:

Combinar com a família que o curso vai exigir dedicação. Envolver as gestões dos órgãos que atua (sic) no objetivo do trabalho que irá fazer. Para obter apoio para produto a ser trabalhado, precisa gerar benefício na sua área de atuação (Alberto).

Pactuar com a esposa sobre a necessidade de reservar horário diário para exercer as atividades do curso (Severino).

A relação entre docentes e discentes é importante principalmente no que concerne à função do professor orientador, destacando-se a necessidade da preparação do corpo docente para atuar como orientador de forma técnica e humana ${ }^{15}$. Esse aspecto foi citado pelos pesquisados deste estudo como estratégia e como aspecto facilitador do processo de estudo:

Reuniões frequentes com nossos orientadores
(Alberto).

Contato frequente com docentes nos fóruns e através do celular, por ligação ou aplicativo (Joana).

O ambiente acadêmico é geralmente descrito como solitário pelo distanciamento físico, social e pela diversidade dos temas de pesquisas, além do tempo dedicado ao estudo. Investigações científicas apontam para modificações nas relações sociais durante o curso ${ }^{14,15}$. Como compensação, os mestrandos procuram novas formas de comunicação, como as redes sociais, as quais aparecem como forma de aproximação para troca de experiências científicas e discussão da relação aluno-professor e orientador-orientando ${ }^{15}$. Esses mecanismos foram utilizados como estratégia pelos mestrandos aqui pesquisados:

Grupo de WhatsApp com os colegas para um dar apoio ao outro (Sebastiana).

Usamos as redes na internet para melhorar o conhecimento, através de compartilhamento de experiência entre colegas (Maria).

\section{Categoria 2: Desafios no gerenciamento da vida}

$\mathrm{Na}$ definição dessa categoria, devem-se destacar dois verbetes que se relacionam fortemente com a existência humana, além de estarem geralmente entrelaçados na vivência das situações que representam. Trata-se de mudança e desafio. Entre os inúmeros significados que cada um possui, ressalta-se a relação do termo mudança com outros, tais como "alteração, desordem, transformação, obstáculo e movimento". Para o verbete desafio, aparecem "oportunidade, conquista e estímulo". Entende-se que nada se modifica sem uma transformação pessoal, e o ser humano é desafiado para mudar durante todo o seu processo de desenvolvimento na vida ${ }^{17}$.

\section{Subcategoria 2.1: Mudanças no cotidiano}

Ao descreverem sua vivência na pós-graduação, os mestrandos, de modo geral, consideraram a gestão do tempo para dar conta do trabalho, do mestrado e das relações familiares como o principal desafio:

Meu maior desafio é a gestão do tempo para dar conta das leituras e atividades das disciplinas. Pensei, em alguns momentos, em desistir por causa desse desafio, mas estou persistindo (Maria).

[...] muita disciplina para acessar as tarefas semanais na Plataforma on-line e por vezes tínhamos que 
pedir adiamento da data de entrega das tarefas pela dificuldade inicial em se adaptar à nova rotina (Severino).

Os profissionais de saúde que cursam os mestrados profissionais em Saúde, na maioria das vezes, não são dispensados de suas atividades laborais. Ao decidirem cursar o programa de pós-graduação, as responsabilidades pelas novas tarefas educacionais são adicionadas às suas responsabilidades profissionais. Sabe-se que, comumente, os profissionais vivenciam cenários precarizados no que tange ao ambiente e às condições e aos processos de trabalho, além de relações sociais de trabalho mediadas por gestões tradicionais ${ }^{18}$.

Pandemias não são facilmente controladas porque o súbito aparecimento e a rápida propagação não possibilitam que ações terapêuticas e preventivas se estabeleçam de imediato e de forma assertiva ${ }^{19,20}$. De tal modo, implicam mudanças no cotidiano, abordadas claramente por meio de desacertos e incertezas tanto no ambiente de trabalho quanto no mestrado que cursam e na própria vida familiar, com interrogações acentuadas sobre o futuro.

A Covid-19 alterou profundamente a minha rotina de trabalho, estudos e inclusive família [...]. Prioridades foram repensadas, energias direcionadas para 0 enfrentamento dessa pandemia. O pouco tempo que já tinha para os estudos não só do mestrado, mas também de atualização profissional deixaram de existir (Alberto).

A pandemia provocou intensa desorganização do setor de trabalho [...] fechamento de setores essenciais para o desenvolvimento do projeto de pesquisa e o distanciamento físico que passou a exigir modificação no modo de pensar nossos encontros, nossos projetos de pesquisa (Pedro).

Desde o primeiro trimestre do ano de 2020, as temperaturas emocionais e físicas das pessoas, principalmente dos profissionais de saúde, aumentaram em intensidade, produzidas pelo medo da pandemia, pela consequente elevação dos níveis de ansiedade e pela ausência de informações sobre como agir para manter-se saudável, o que, evidentemente, incluía familiares, usuários, amigos e pessoas vinculadas afetivamente a eles.

A pesquisa mostrou que houve (e continua acontecendo) um efeito revolucionário produzido pelas mudanças repentinas desencadeadas pela pandemia na vida das pessoas, provocando um impacto nas emoções vivenciadas na rotina diária como um todo.

[...] de repente, nos vimos diante da indagação do que iria acontecer em relação ao futuro [...] o acompanhamento do noticiário de horror, de mortes de amigos e familiares dos amigos, nos levaram a pensarmos sobre a nossa própria existência, sobre a finitude, sobre o que fazermos para ajudar tantas pessoas que a nós recorriam, enquanto profissionais de saúde, em busca de respostas, de socorro, de alento para as perdas a que todos foram submetidos (João).

Mudança radical da rotina de atividades, planos, prioridades, expectativas, sentimentos, confiança. Como se todos os planos e prioridades tivessem deixado de existir ou perdido a importância (Marta).

\section{Subcategoria 2.2: Impacto nas emoções}

Os estudos sobre a pandemia têm mencionado os efeitos nas emoções das pessoas, inclusive nos profissionais de saúde, convocados para continuar exercendo suas práticas assistenciais aos pacientes, independentemente do medo de infectar-se e da separação forçada de entes queridos para preservá-los da contaminação ${ }^{21,22}$. Afora isso, são confrontados por dilemas éticos em relação à pouca disponibilidade de recursos para assistir vários pacientes e fornecer cuidados àqueles mais gravemente doentes ${ }^{21}$.

Usando palavras mais racionais ("estamos tendo que nos reinventar"; "tempo escasso e cansaço mental") ou carregadas de emotividade, os profissionais médicos pesquisados demonstraram estar mobilizados emocional e fisicamente, e, portanto, propensos a apresentar sobrecargas que podem interferir mais adiante em sua saúde como um todo.

Os profissionais de saúde que lidam diretamente com a situação de risco e sob pressão da situação enfrentada no trabalho costumam descuidar-se da própria saúde, podendo apresentar alterações em sua vida, em sua saúde física e mental, uma vez que há relação direta entre o enfrentamento da doença e o aparecimento de quadros alterados do estado emocional, como estresse, ansiedade, insônia e sintomatologia depressiva ${ }^{11}$.

Neste estudo, surgiram afirmações pouco verbalizadas no universo de profissionais médicos, como "medo" e "perda de importância de planos para o futuro", o que demonstra o estado psíquico de vulnerabilidade a que estão submetidos.

Uma rede de solidariedade, com vistas a um suporte psicossocial e como medida protetiva ao agravamento dos quadros de ansiedade, é fundamental para a continuidade dos processos formativos, especialmente nesse cenário pandêmico ${ }^{23}$. Até a oferta de cuidado em saúde deve ser realizada de maneira não presencial ${ }^{24}$.

\section{Categoria 3: Crescimento pessoal e profissional}

Crescer ou desenvolver-se é um processo de busca de habilidades e competências visando alcançar objetivos. $\mathrm{O}$ desenvolvimento pessoal abrange o alcance de habilidades específicas e, em momentos de grandes mudanças, exige a utilização de capacidades adaptativas no sentido de conseguir 
sobreviver ao momento vivido ${ }^{25}$.

O mestrado possibilitou enfrentamentos que levaram ao emprego de tempo/energia, resultando em redimensionamento de planos pessoais, familiares e profissionais. Os mestrandos pesquisados teceram comentários sobre esse processo:

[...] experiência de extremo crescimento pessoal $e$ profissional. [...] Estou conseguindo um upgrade sem precedente em meu caminhar existencial, seja na relação com meus alunos, na convivência com meus mestres, no atendimento aos meus pacientes na unidade de saúde, só enxergo ganhos em todos os processos (Joana).

Momentos de muito aprendizado, produção $e$ descobertas intercalados com momentos de frustrações intensas, sensação de limitações ou até incompetência (Severino).

A pandemia acrescentou aspectos nesse processo de crescimento. O que já era conhecido como mestrando, como sentimentos contraditórios de amor/ódio, desespero/ esperança ${ }^{26}$, foi acrescido por algo maior, novo e desafiador no sentido da continuidade do viver:

Tínhamos novo mundo, nova forma de viver, de conviver, de estudar. Falta de resposta do novo amanhã. O ensino? O atendimento ao público? Seremos acometidos pela Covid19? Sobreviveremos? Reflexões nos deixaram perplexos; passado o choque, veio a descoberta de que segue a vida e caminhar é preciso, com cuidados maiores (João).

Certeza de crescimento, avanços, em todos os setores: ensino, pesquisa, serviço, que contribuiu para seguir o nosso mestrado, mesmo à luz da pandemia (Pedro).

Nos reinventamos para aperfeiçoar e aprender. Não paramos, tivemos que avançar cognitivamente, estudando, pesquisando, construindo, publicando (Maria).

Nessas falas, nota-se a presença da resiliência, termo oriundo do latim resiliens que significa voltar ao estado normal, recuperar-se. A resiliência vem sendo estudada desde o século passado pela física, engenharia, psicologia, sociologia e mais recentemente pela administração. Na psicologia, o termo ganhou amplitude, com estudos sobre indivíduos e até grupos que, após adversidades sofridas, recuperaram-se e até se tornaram mais fortes. Os mestrandos, ao dizerem "Tínhamos novo mundo, nova forma de viver [...]. Sobreviveremos? [...] passado o choque, veio a descoberta de que segue a vida e caminhar é preciso [...]" e "Nos reinventamos para aperfeiçoar e aprender", demonstraram ter habilidade de recuperação após eventos estressantes ou crises danosas ${ }^{25,27}$.

\section{CONCLUSÃO}

As três categorias e as quatro subcategorias relatadas pelos médicos pesquisados expressaram a complexa relação entre a atuação profissional na APS e a continuidade das atividades do mestrado, que possui uma dinâmica própria. Tudo isso em um contexto de atipicidade histórica/sanitária - $a$ pandemia. Os desafios impostos fecundaram sentimentos que podem resultar em adoecimento físico e psíquico. Tal contexto exigiu a adoção de mudanças no cotidiano desses médicos, com possibilidade de crescimento e amadurecimento, sobretudo quanto à resiliência. Ademais, o PROFSAÚDE contribuiu para o desenvolvimento de habilidades e competências que têm ajudado os médicos a enfrentar a Covid-19.

Como diz a música de Chico Buarque, "Apesar de você, amanhã há de ser outro dia".

\section{CONTRIBUIÇÃO DOS AUTORES}

Divanise Suruagy Correia, Maria das Graças Monte Mello Taveira e Michael Ferreira Machado foram responsáveis pela conceituação do trabalho, pela curadoria de dados, pela análise formal, pela investigação, pela metodologia e pela redação (rascunho original, revisão e edição). Celso Marcos da Silva e Cristina Camelo Azevedo participaram da investigação e redação do artigo. Carlos Dornels Freire de Souza participou da revisão de conteúdo e da edição do artigo. Todos os autores aprovaram a versão final de publicação.

\section{CONFLITO DE INTERESSES}

Os autores declaram não haver conflito de interesses neste estudo.

\section{FINANCIAMENTO}

Declaramos que não houve financiamento para a realização desta pesquisa.

\section{REFERÊNCIAS}

1. Zhou F, Yu T, Du R, Fan G, Liu Y, Liu Z, et al. Clinical course and risk factors for mortality of adult inpatients with COVID-19 in Wuhan, China: a retrospective cohort study. Lancet. 2020;395:1054-62.

2. Brasil. Boletim COE COVID-19 no 13: Situação epidemiológica - Doença pelo coronavírus 2019 [acesso em 3 ago 2020]. Disponível em: https:// portalarquivos.saude.gov.br/images/pdf/2020/April/21/BE13---Boletimdo-COE.pdf.

3. World Health Organization. WHO Coronavirus Disease (COVID-19) Dashboard [acesso em 3 ago 2020]. Disponível em: https://covid19.who. int.

4. Brasil. Constituição da República Federativa do Brasil. Brasília, DF: Senado Federal, Centro Gráfico, 1988 [acesso em 3 ago 2020]. Disponível em: http://www.planalto.gov.br/ccivil_03/constituicao/constituicao.htm.

5. Souza CDF, Gois-Santos VT, Correia DS, Martins-Filho PR, Santos VS. The need to strengthen primary health care in Brazil in the context of the COVID-19 pandemic. Braz Oral Res. 2020;34:e047. 
6. Souza CDF. Programa Saúde da Família - PSF: a ação do estado, o cenário de implantação e a importância do território para a sua efetivação. Hygeia. 2014;10(18):207-15.

7. Brasil. Lei $n^{\circ} 12.871$, de 22 de outubro de 2013. Institui o Programa Mais Médicos, altera as Leis no 8.745 , de 9 de dezembro de1993, e $n^{\circ}$ 6.932, de 7 de julho de 1981, e dá outras providências [acesso em 3 ago 2020]. Disponível em: http://www.planalto.gov.br/ccivil_03/_Ato20112014/2013/Lei/L12871.htm\#: :text=Institui\%200\%20Programa\%20 Mais\%20M\%C3\%A9dicos, 1981\%2C\%20e\%20d\%C3\%A1\%20outras\%20 provid\%C3\%AAncias.\&text=VIII\%20\%2D\%20estimular\%20a\%20realiza\%C3\%A7\%C3\%A30\%20de\%20pesquisas\%20aplicadas\%20ao\%20SUS.

8. Brasil. Mestrado Profissional em Saúde da Família - PROFSAÚDE [acesso em 3 ago 2020]. Disponível em: http://profsaude-abrasco.fiocruz.br/ sobre-programa.

9. Lalande A. Vocabulário técnico e crítico da filosofia. 2a ed. São Paulo: Martins Fontes; 1996.

10. Malheiros BT. Metodologia de pesquisa em educação. Rio de Janeiro: LTC; 2011.

11. OliveiraWA, Oliveira-Cardoso EA, Silva JL, Santos MA. Impactos psicológicose ocupacionais das sucessivas ondas recentes de pandemias em profissionais da saúde: revisão integrativa e lições aprendidas. Estud Psicol (Campinas). 2020;37:e200066 [acesso em 3 ago 2020]. Disponível em: http://www.scielo. br/scielo.php?script=sci_arttext\&pid=S0103-166X2020000100503\&lng=pt \&nrm=iso.

12. Camus A. A peste [acesso em 3 ago 2020]. Disponível em: https://letraslyrics.com.br/PDF/Albert-Camus/Albert-Camus-A-Peste.pdf.

13. Rodrigues NH, Silva LGA. Gestão da pandemia coronavírus em um hospital: relato de experiência profissional. J Nurs Health. 2020;10(4):e20104004.

14. Moreira DA, Tibães HB, Brito MJM. Pleasure-suffering duality in stricto sensu graduate programs in nursing: between bridges and walls. Rev Bras Enferm. 2020;73(2):e20180533.

15. Meurer AM, Lopes IF, Antonelli RA, Colauto RD. Experiências na pósgraduação, comportamento nas redes sociais e bem-estar. Educ Real. 2020;45(1):e86158.

16. Cardoso MMFL. A evasão discente no Programa de Pós-Graduação em Educação da Universidade Federal de Santa Catarina [dissertação]. Florianópolis: Universidade Federal de Santa Catarina Dissertação de Mestrado; 2017.
17. Senge PM. A dança das mudanças. 3a ed. Rio de Janeiro: Campus; 1999.

18. Santos-Filho SB. Um olhar sobre o trabalho em saúde nos marcos teóricopolíticos da saúde do trabalhador e do HumanizaSus: o contexto do trabalho no cotidiano dos serviços de saúde. In: Santos-Filho SB, de Barros, MEB. Trabalhador da saúde: muito prazer! Protagonismo dos trabalhadores na gestão do trabalho em saúde. ljuí: Unijuí; 2007.

19. Malvezzi S, Hazzin I, Bizzaro L. A psicologia no enfrentamento da revolução da COVID-19. In: Bentivi DRC, organizadora. Retrato da psicologia brasileira no cenário da COVID-19. Porto Alegre: Artmed; 2020. (O trabalho e as medidas de contenção da COVID-19: contribuições da psicologia organizacional e do trabalho, v. 3).

20. Machado MF, Quirino TRL, Correia DS, Taveira MGMM, Souza CDF, Lima JR. Atenção primária à saúde no enfrentamento à COVID-19: análise dos planos estaduais de contingência do Nordeste. Rev Port Saúde e Sociedade. 2020;5(1):1286-98.

21. Ramírez-Ortiz J, Castro-Quintero D, Lerma-Córdoba C, Yela-Ceballos F, Escobar-Córdoba F. Consecuencias de la pandemia Covid-19 en la salud mental asociadas al aislamiento social. Rev Colomb Anestesiol. 2020;48(4):e930 [acesso em 7 ago 2020]. Disponível em: http://www. scielo.org.co/pdf/rca/v48n4/es_2256-2087-rca-48-04-e301.pdf

22. Pereira MD, Oliveira LC, Costa CFT, Bezerra CMO, Santos CKA, Dantas EHM. The COVID-19 pandemic, social isolation, consequences on mental health and coping strategies: an integrative review. Research, Society and Development. 2020;9(7):1-35.

23. Asmundson GJG, Taylor S. Coronaphobia: fear and the 2019-nCoV outbreak. J Anxiety Disord. 2020; 70:102-196.

24. Asmundson GJG, Taylor $S$. How health anxiety influences responses to viral outbreaks like COVID-19: what all decision-makers, health authorities, and health care professionals need to know. J Anxiety Disord.2020;71:102-211.

25. Oliveira ATC, Morais NA. Resiliência comunitária: um estudo de revisão integrativa da literatura. Trends Psychol. 2018;26(4):1731-45.

26. Ambrosetti NB, Calil AMGC. Contribuições do mestrado profissional em Educação para a formação docente. Revista Reflexão e Ação. 24(3):85-104.

27. Sabbag P. Resiliência:competência para enfrentar situações extraordinárias na sua vida profissional [e-book]. Rio de Janeiro: Alta Books; 2017. 